\title{
ELEMENTOS PROTETORES DO LEITE MATERNO NA PREVENÇÃO DE DOENÇAS GASTRINTESTINAIS E RESPIRATÓRIAS
}

\author{
PROTECTIVE ELEMENTS OF BREAST MILK IN THE
EVENTION OF GASTROINTESTINAL AND RESPIRATORY \\ PROTECTIVE ELEMENTS OF BREAST MILK IN THE
PREVENTION OF GASTROINTESTINAL AND RESPIRATORY \\ DISEASES
}

Adriana Passanha ${ }^{1}$

Ana Maria Cervato-Mancuso ${ }^{2}$

Maria Elisabeth Machado Pinto e Silva ${ }^{2}$

Passanha, A; Cervato-Mancuso, AM.; Silva MEMP. Elementos protetores do leite materno na prevenção de doenças gastrintestinais e respiratórias. Rev. Bras. Cresc. e Desenv. Hum. 2010; 20(2): 351-360.

\section{Resumo}

Objetivos: identificar os elementos protetores do leite materno que atuam na prevenção de doenças gastrintestinais e respiratórias. Fonte dos dados: a busca foi realizada nas bases de dados Bireme, Lilacs, Medline e Scielo, utilizando os descritores leite materno, doenças gastrintestinais e doenças respiratórias, com limites de idiomas (português, inglês e espanhol) e de período (1996 a 2009). Foram selecionados 46 textos por atenderem aos objetivos deste trabalho. Síntese dos dados: a IgA é imunoglobulina com maior capacidade protetora contra ambos os tipos de doenças, por sobreviver às mucosas intestinal e respiratória. O leite materno também possui outras imunoglobulinas, anticorpos, oligossacarídeos, lipídeos, peptídeos bioativos, entre outros constituintes exclusivos com mecanismos específicos que, além da proteção contra essas doenças, estimulam o desenvolvimento do sistema imune do lactente. Assim, nenhum outro leite possui essas propriedades e podem até ser a causa destas doenças. Campanhas e ações em Saúde Pública que incentivam o aleitamento materno devem ser continuamente desenvolvidas e estimuladas, considerando todos os benefícios que o mesmo proporciona.

Palavras-chave: leite humano; gastroenteropatias; doenças respiratórias; aleitamento materno.

1 Nutricionista, aprimoranda na área de Nutrição em Saúde Pública pela Faculdade de Saúde Pública - USP.

2 Professoras Doutoras do Departamento de Nutrição da Faculdade de Saúde Pública - USP.

Faculdade de Saúde Pública - USP - Departamento de Nutrição.

Av. Dr. Arnaldo, 715. Cerqueira César. São Paulo - SP. Cep: 01246-904

Autor responsável: Adriana Passanha. E-mail: adriana.passanha@gmail.com

Endereço para correspondência: Av. Dr. Arnaldo, 715. Cerqueira César. São Paulo - SP. CEP: 01246-904.

Conflito de interesse: nada a declarar. 


\begin{abstract}
Objective: to identify the protective elements of breast milk that work in the prevention of gastrointestinal and respiratory diseases. Sources: the search was performed on Bireme, Lilacs, Medline and Scielo databases, using keywords breast milk, gastrointestinal disease and respiratory disease, with limits of languages (English, Portuguese and Spanish) and period (1996 to 2009). 46 papers were selected for achieving the objectives of this work. Summary of the findings: the IgA is the immunoglobulin with more protective capability against both types of disease, to survive the intestinal and respiratory mucosa. Breast milk also contains other immunoglobulins, antibodies, oligosaccharides, lipids, bioactive peptides, among other components with unique mechanisms that besides the protection against these diseases, stimulate the development of infants' immune systems. No other milk has these properties, and may even be the cause of these diseases. Campaigns and actions in Public Health to encourage breastfeeding should be continuously developed and encouraged considering all the benefits it provides.
\end{abstract}

Key words: milk, human; gastrointestinal diseases; respiratory tract diseases; breast feeding.

\section{INTRODUÇÃO}

O aleitamento materno representa uma das experiências nutricionais mais precoces do recém-nascido ${ }^{1}$. Nenhum outro alimento ou leite industrializado modificado é capaz de oferecer ao bebê todos os ingredientes do leite materno. Este alimento apresenta composição específica que se ajusta às necessidades nutricionais do lactente, e é compatível com suas limitações metabólicas e fisiológicas ${ }^{2,3}$. Ademais, não representa ônus para o orçamento familiar $^{4,5}$.

Embora a frequência e a duração do aleitamento venha evoluindo favoravelmente durante os últimos 30 anos $^{6}$, e apesar do consenso acerca das inúmeras vantagens do aleitamento materno e da mobilização mundial nas últimas décadas para recuperação da cultura da amamentação, o desmame precoce ainda é uma prática comum em todo o mundo ${ }^{7,8}$.

Os índices da frequência e duração do aleitamento materno vêm contrariando a eficácia dos esforços de inúmeros programas oficiais e não governamentais, de incentivo ao aleitamento materno em todo o país ${ }^{9}$. Apenas $35 \%$ dos lactentes menores de quatro meses são amamentados exclusivamente e o desmame precoce ainda está associado a altos índices de mortalidade infantil por desnutrição e diarreia ${ }^{8}$.

Estimativas recentes quanto a diversas formas de ação e suas consequências para a saúde da criança mostraram que a promoção do aleitamento materno exclusivo é a intervenção isolada em saúde pública com o maior potencial para a diminuição da mortalidade na infância ${ }^{10}$, já que o aleitamento materno exclusivo contribui para reduzir a morbimortalidade infantil ${ }^{11}$. De acordo com Betrán et al. ${ }^{12}, 13,9 \%$ de todas as causas de mortalidade infantil na América Latina podem ser prevenidas através do aleitamento exclusivo em lactentes de 0 a 3 meses e em aleitamento parcial no primeiro ano de vida.

No Brasil, a maioria das mulheres inicia o aleitamento materno; entretanto, mais da metade das crianças já não se encontra em amamentação exclusiva no primeiro mês de vida, o que contraria a recomendação da $\mathrm{OMS}^{13}$ 
de que o aleitamento exclusivo deve durar até os seis meses de idade ${ }^{5}$.

O período entre o nascimento e os dois anos de idade é muito crítico para a promoção do crescimento, da saúde e desenvolvimento ótimos. $O$ aleitamento materno é uma ferramenta privilegiada para assegurar às crianças os melhores resultados possíveis e transitar com êxito esse período tão vulnerável da vida, de maneira a contribuir com um melhor desempenho nas etapas seguintes ${ }^{14}$, auxiliando, também, na prevenção de doenças na infância e na idade adulta ${ }^{15}$.

A amamentação oferece inúmeros benefícios para a saúde da criança, sendo a melhor maneira capaz de promover seu desenvolvimento integral, pois o leite materno fornece os nutrientes necessários para a criança iniciar uma vida saudável ${ }^{16}$. O leite humano supre as necessidades do lactente até o sexto mês de vida ${ }^{17,18}$, e durante o primeiro ano da criança é um dos meios mais eficientes de atender seus aspectos nutricionais e imunológicos ${ }^{19}$.

Além da composição adequada de nutrientes, o leite materno possui outros componentes que atuam na defesa do organismo do lactente, como imunoglobulinas, fatores antiinflamatórios e imunoestimuladores. Seus mecanismos incluem atividade específica contra agentes infecciosos, crescimento celular da mucosa intestinal aumentando a resistência às infecções, entre outros ${ }^{2,3}$. Há relatos de aproximadamente 250 elementos de proteção no leite humano, além de fatores de crescimento do trato gastrintestinal ${ }^{19}$.

A lactação diminui a incidência e/ou a gravidade de diarreia, botulismo, enterocolite necrotizante, alergias, doenças infecciosas e respiratórias, entre outras doenças ${ }^{3,5,11,12,20,21}$, incluindo as auto-imunes ${ }^{20}$, como também estimula o desenvolvimento adequado do sistema imunológico do bebê ${ }^{18}$.

Outros tipos de leite aumentam os riscos de desenvolvimento de doenças e alergias ${ }^{17}$, e podem ocasionar lesões no intestino imaturo do lactente ${ }^{22}$. A porta de entrada da maioria das in- fecções no ser humano é representada pelas superfícies mucosas, principalmente dos tratos gastrintestinal e respiratório. Através da alimentação e da respiração o organismo entra em contato com microorganismos patogênicos, assim como substâncias potencialmente alergênicas ou nocivas $^{23}$. A amamentação exclusiva salva milhões de crianças a cada ano por prevenir doenças infecciosas agudas e crônicas, principalmente respiratórias e intestinais ${ }^{7}$.

Considerando todos os efeitos benéficos da amamentação e a proteção exclusiva que esta oferece contra diversas doenças, o objetivo deste estudo é identificar os elementos protetores presentes no leite materno que atuam na prevenção de doenças gastrintestinais e doenças respiratórias.

\section{METODO}

Trata-se de uma revisão sobre o tema, onde as informações foram obtidas por meio de rastreamento literário sistemático, empregando-se a técnica booleana utilizando a palavra and e os seguintes descritores: leite materno and doenças gastrintestinais; e leite materno and doenças respiratórias. Para tanto, utilizaram-se fontes de pesquisa como publicações específicas e os provedores de pesquisa Bireme, Lilacs, Medline e Scielo. Como critérios de busca foram utilizados limites de idiomas (português, espanhol e inglês), e de período (1996 a 2009).

Com estes limites de pesquisa, foram rastreados 302 materiais. Destes, foram selecionados 46 por atenderem aos objetivos do presente trabalho.

\section{ELEMENTOS DE PROTEÇÃO DO LEI- TE MATERNO}

Recém-nascidos e lactentes, sobretudo nos primeiros seis meses de vida, são mais 
vulneráveis a infecções, devido à imaturidade do sistema imunológico e à maior permeabilidade intestinal. Assim, durante um período crítico de relativa incompetência imunológica, o leite humano apresenta atributos de qualidade frente às suas necessidades imunobiológicas, protegendo-os de diversas doenças ${ }^{2,23,24}$.

Tanto a idade cronológica quanto o estado nutricional das mães não influenciam de forma significante as concentrações de proteínas totais, albuminas, IgG e IgA presentes no colostro $^{25}$. A glândula mamária parece ter mecanismos específicos para regular a concentração de oligoelementos no leite, mesmo em condições específicas de variação de dieta materna ${ }^{26}$.

No entanto, a composição do leite de mãe de prematuro apresenta algumas diferenças, pois promove efeitos anti-inflamatórios mais exuberantes do que o leite de mãe de recém-nascido a termo ${ }^{27}$. Essa composição diferenciada pode prover imunoproteção via maturação do intestino do prematuro ${ }^{27}$, já que pré-termos têm maior risco de desenvolver complicações no trato gastrintestinal e respiratório ${ }^{28}$. As propriedades nutricionais e anti-infecciosas do leite da mãe de pré-termos são adequadas às necessidades fisiológicas e imunológicas do imaturo tubo digestivo do recém-nascido, com maior quantidade de IgA, lisozima e lactoferrina ${ }^{2}$.

As propriedades antiinfecciosas do leite humano são representadas através dos componentes solúveis e celulares. Os solúveis incluem imunoglobulinas, IgA, IgM, IgD, IgE, IgG, com predominância da IgA, lisozima, lactoferrina, componentes do sistema do complemento (C3, C4), peptídeos bioativos, oligossacarídeos e lipídios (fator antiestafilococos e inativação de vírus). Os componentes celulares imunologicamente ativos são constituídos por fagócitos polimorfonucleares, linfócitos, macrófagos, nucleotídeos, plasmócitos e células epiteliais ${ }^{2,18,27,29-32}$.

O leite humano possui também lactoperoxidase, que oxida bactérias com ação antimicrobiana ${ }^{18,29}$. Os macrófagos e linfócitos são responsáveis pela fagocitose e pela produção de fatores do complemento ${ }^{27}$.

Os anticorpos presentes no leite materno são dirigidos a inúmeros microorganismos com os quais a mãe entrou em contato durante toda sua vida, representando um tipo de "repertório" imunológico. A maior parte desses microorganismos já entrou em contato com as superfícies mucosas do aparelho gastrintestinal ou respiratório maternos ${ }^{20}$.

Além dos anticorpos, o colostro humano contém inúmeros fatores bioquímicos e células imunocompetentes, que interagem entre si e com a mucosa dos tratos digestivo e respiratório do lactente, conferindo não apenas imunidade passiva, como também estímulo ao desenvolvimento e maturação do próprio sistema imune de mucosas do neonato ${ }^{11}$.

Os glicoconjugados e oligossacarídeos possuem atividade antiaderente para inúmeros microorganismos causadores de doenças gastrintestinais e respiratórias ${ }^{23}$. O leite de vaca não possui nenhum elemento imunológico que seja favorável ao lactente ${ }^{27}$, e a administração de alimentos ou suplementos pré-lácteos aumenta o risco de infecções no lactente ${ }^{4}$.

\section{DOENÇAS GASTRINTESTINAIS}

Já no ano de 1989, quando foi publicado o estudo de Brown et al. ${ }^{33}$, sabia-se que o uso de chupetas e a administração de chás e outros fluidos não-nutritivos a lactentes, além de favorecerem o desmame precoce, predispõem o aparecimento de diarreia, pelo risco de contaminação a que ficam expostos.

O prolongamento do aleitamento materno traz benefício adicional no final do primeiro e segundo anos de vida, quando a incidên- 
cia de diarreia alcança seu valor máximo ${ }^{17}$. A presença de leite no lúmen intestinal estimula o desenvolvimento de sua mucosa ${ }^{17,28} \mathrm{e}$ a atividade da enzima lactase ${ }^{34}$. De acordo com a revisão de Toma \& Rea ${ }^{10}$, bebês amamentados exclusivamente apresentaram menor morbidade por diarreia em comparação com aqueles que receberam aleitamento materno junto com alimentos complementares aos três/ quatro meses.

Desde as primeiras horas de vida diversas linhagens de Escherichia coli colonizam o intestino humano, passando a fazer parte da sua flora normal. No entanto, algumas destas podem causar doença intestinal grave ${ }^{23}$. No recém-nascido, a imaturidade do epitélio intestinal, a baixa acidez gástrica e a menor atividade de enzimas digestivas não constituem uma barreira muito eficiente contra a entrada de microorganismos ${ }^{35}$.

A partir da década de 1970, com a descoberta do fator bifidus, torna-se cada vez mais conhecido o mecanismo pelo qual ocorre a proteção da mucosa intestinal contra os agentes patogênicos. Vários tipos de oligossacarídeos e glicoconjugados presentes no leite materno (conhecidos como agentes prebióticos) estimulam a colonização do intestino por microorganismos benéficos. Esses agentes atuam na primeira etapa essencial da patogênese, ao impedir que um microorganismo se fixe na parede celular ${ }^{36}$.

Crianças amamentadas exclusivamente apresentam uma flora intestinal benéfica, com maior quantidade de bifidobactérias e menos Clostridium dificile e Escherichia coli, de acordo com Penders et al. ${ }^{37}$. Segundo o estudo desses autores, que examinaram as fezes de 1.032 bebês holandeses de até um mês de idade, dentre os principais fatores determinantes da microflora intestinal no início da vida está a alimentação infantil. Já em 1905, havia registros de diferenças na composição da microflora intestinal de crianças amamentadas em comparação a crianças desmamadas.
Os carboidratos presentes no leite humano são os oligossacarídeos e a lactose. Os oligossacarídeos, na presença de peptídeos, formam um fator bífido (carboidrato com nitrogênio dialisável). No meio rico em lactose, produzirá ácido láctico e succínico, o que diminui o $\mathrm{pH}$ intestinal, tornando o local desfavorável ao crescimento de bactérias patogênicas, fungos e parasitas. Sendo assim, a lactose também exerce fator protetor ao desenvolvimento de afecções gastrintestinais, promovendo essa colonização benéfica ${ }^{2,38}$.

Esses oligossacarídeos nitrogenados possibilitam a instalação da flora bífida que impede, por ação seletiva, que novas bactérias recém-chegadas à luz do intestino e os potenciais agentes patogênicos da diarreia, como a E. coli, dentre outras enterobactérias, colonizem o trato intestinal ${ }^{18,29,31}$.

A mucina é uma proteína presente no colostro ligada aos glóbulos de gordura. Sua principal função é inibir a adesão bacteriana ao epitélio intestinal ${ }^{39}$.

Algumas gorduras poliinsaturadas, como os ácidos araquidônico e linoleico, têm importância na síntese de prostaglandinas envolvidas em funções biológicas que atuam sobre a digestão e sobre a maturação de células intestinais, propiciando a queda da prevalência de alergia intestinal e contribuindo para a defesa do lactente ${ }^{2,40}$. Os lipídeos presentes no leite humano são hidrolisados em ácidos graxos e monoglicerídeos que têm atividade sobre alguns tipos de vírus, de bactérias e de protozoários $^{39}$.

Nucleotídeos, glutamina e lactoferrina presentes no leite materno influenciam o desenvolvimento gastrintestinal e as defesas do organismo ${ }^{3,21,35,41}$. A glutamina age como principal combustível para o crescimento do epitélio intestinal em períodos de estresse ${ }^{28}$.

Uma das funções da lactoferrina é quelar íons ferro, que são essenciais para a multiplicação de microorganismos patogênicos, diminuindo assim sua biodisponibilidade no 
microambiente intestinal, processo que é favorecido pela presença de bicarbonato no leite humano ${ }^{39,42}$. A lactoferrina é encontrada intacta tanto nas fezes quanto na urina de crianças amamentadas, podendo assim exercer um papel protetor sistêmico ${ }^{23}$.

A lisozima é uma enzima com ação bactericida, interagindo sinergicamente com lactoferrina e $\operatorname{IgA}{ }^{39,42}$. A proteção contra gastrenterites se traduz numa menor incidência de diarreias, pela presença de anticorpos IgA presentes no leite materno, reativos com patógenos ou toxinas ${ }^{20}$.

A IgA é a principal imunoglobulina do colostro $^{23,28,43}$. Ela está presente no intestino de bebês alimentados com leite humano, impedindo a invasão e a aderência de vírus e bactérias na mucosa intestinal, e neutralizando toxinas e fatores de virulência ${ }^{28}$.

A principal ação da IgA é se ligar a microorganismos e macromoléculas, inibindo a interação entre bactérias e células epiteliais, impedindo sua aderência às superfícies mucosas, prevenindo o contato de patógenos com o epitélio ${ }^{44}$. Dessa forma, a IgA protege a mucosa contra diarréias, pois forma um revestimento protetor nas superfícies mucosas do lactente ${ }^{23}$.

Os anticorpos IgA do colostro resistem ao trato gastrintestinal do recém-nascido e podem ser encontrados intactos nas fezes, preservando a mesma reatividade contra antígenos que apresentavam quando no colostro da mãe, conservando sua atividade anti-infecciosa ao longo de todo o trato gastrintestinal do recémnascido ${ }^{23,39,42,45}$. Sua estrutura peculiar promove a essa classe de anticorpos maior resistência à ação de enzimas proteolíticas, abundantes nas secreções mucosas ${ }^{44}$.

As outras imunoglobulinas são encontradas no colostro e no leite humano em concentrações bem mais baixas que a IgA. Dentre elas, destaca-se a IgM como a segunda mais abundante. Quando não há IgA suficiente no leite materno a IgM atua como mecanismo compensatório. Sendo assim, anticorpos IgM podem ter um importante papel na defesa das superfícies mucosas do lactente ${ }^{23}$.

No decorrer da lactação, mesmo com o declínio da secreção de IgA no leite materno, a atividade biológica de inibição da adesão bacteriana permanece inalterada. Esse dado é compatível com o fato de que as crianças permanecem protegidas contra gastrenterites durante todo o período de aleitamento. Diarreias são mais frequentes após o desmame, independente da idade em que ocorram. Por sua vez, esses dados reforçam a importância do leite materno para recém-nascidos prematuros e pequenos para a idade gestacional ${ }^{23}$.

A caseína do leite humano é também um de seus vários constituintes que ajudam a proteger a criança de infecções gastrintestinais, impedindo a aderência de bactérias às células da mucosa intestinal ${ }^{2}$.

Anticorpos secretores reativos com os fatores de virulência de algumas bactérias são capazes de inibir a adesão bacteriana à mucosa intestinal e com isso impedir a colonização do hospedeiro, impedindo a sequência de eventos que culminaria em infecção e diarreia. Esse é um importante mecanismo de proteção conferido pelo leite materno, que deve ocorrer em casos de diversas infecções iniciadas pela adesão de microorganismos às superfícies mucosas ${ }^{45}$.

\section{DOENÇAS RESPIRATÓRIAS}

A amamentação exclusiva protege as crianças pequenas de evoluírem para quadros mais graves de infecção respiratória ${ }^{10,46}$. Quando predominante por pelo menos seis meses e até um ano de idade também pode reduzir a prevalência de infecções respiratórias na infância ${ }^{47,48}$. O leite materno é capaz de reduzir a exposição e a absorção intestinal de alergênicos responsáveis por doenças respiratórias ${ }^{49,50}$. 
Os efeitos protetores da amamentação contra infecções do ouvido e pulmão têm-se tornado mais evidentes nos últimos anos. Nesse particular, cumpre importante papel a IgA secretora, um anticorpo resultante da resposta da mãe à exposição prévia a agentes infecciosos. Ela tem como característica sobreviver nas membranas da mucosa respiratória e ser resistente à digestão proteolítica. Além de impedir que agentes patogênicos se fixem nas células da criança amamentada, ela limita os efeitos danosos do processo inflamatório ${ }^{32,49,51}$.

As concentrações de citocinas têm um papel fundamental na imunogenicidade do leite materno. As citocinas IL-4, IL-5 e IL-13, mais envolvidas com a produção de IgE e indução de resposta de eosinófilos, podem proteger o lactente contra doenças respiratórias ${ }^{52}$. O fator de crescimento transformador beta, uma das citocinas predominantes no leite humano, aumenta a capacidade do lactente de produzir IgA ${ }^{53}$.

Os oligossacarídeos bloqueiam pneumococos pelas células receptoras da faringe ${ }^{28}$. Diversos tipos de anticorpos protegem contra vírus causadores de bronquite. Os lípideos e algumas macroglobulinas possuem ação antiviral, protegendo o lactente contra o vírus influenza. Essas macroglobulinas também protegem o recém-nascido de agentes causadores de infecção respiratória alta aguda ${ }^{54}$.

\section{REFERÊNCIAS}

1. Simon VGN, Souza JMP, Souza SB. Aleitamento materno, alimentação complementar, sobrepeso e obesidade em pré-escolares. Rev Saúde Pública. 2009; 43: 60-9.

2. Lamounier JA, Vieira GO, Gouvêa LC. Composição do Leite Humano - Fatores Nutricionais. In: Rego JD. Aleitamento Materno. Rio de Janeiro: Atheneu; 2001. p. 47-58.
O CD14 solúvel está presente em altas concentrações no leite materno e tem importante papel na indução da resposta de linfócitos T auxiliares a bactérias, podendo também proteger contra o desenvolvimento de alergias ${ }^{55}$. O alto nível de proteína eosinofílica catiônica também proporciona essa proteção. ${ }^{56}$ Os linfócitos protegem o lactente contra doenças respiratórias, principalmente contra a asma ${ }^{57-59}$.

O aleitamento materno também diminui a involução da glândula do timo durante a infância ${ }^{60}$, o que consequentemente estimula os efeitos das células $T$, protegendo o lactente de doenças respiratórias ${ }^{48}$.

Assim, o leite materno é o único alimento capaz de proteger o lactente de diversas doenças nos primeiros meses de vida, pois é rico em compostos nutricionais e imunológicos que conferem essa proteção. Outros tipos de leites, fórmulas ou alimentos, além de não conter estes componentes protetores, podem causar doenças no recém-nascido.

Campanhas e ações em Saúde Pública que incentivam o aleitamento materno devem ser continuamente desenvolvidas e estimuladas, tendo em vista todos os efeitos benéficos que o mesmo proporciona.

3. Ribeiro LC, Kuzuhara JSW. Lactação. In: Silva SMCS, Mura JD’AP. Tratado de alimentação, nutrição e dietoterapia. São Paulo: Roca, 2007. p. 293-318.

4. OMS - Organização Mundial da Saúde. Organização Pan-Americana da Saúde. Evidências científicas dos dez passos para o sucesso no aleitamento materno. Brasília; 2001.

5. WHO - World Health Organization. The optimal duration of exclusive breastfeeding: a systematic review. Geneva; 2001. 
6. Abrão ACFV. Amamentação: uma prática que precisa ser aprendida. Pediatria (São Paulo). 2006; 28: 79-80.

7. Venâncio SI, Escuder MML, Kitiko P, Rea MF, Monteiro CA. Frequência e determinantes do aleitamento materno em municípios do Estado de São Paulo. Rev Saúde Pública. 2002; 36: 313-8.

8. WHO - World Health Organization. Global strategy for infant nf young child feeding. Geneva; 2003.

9. Silva IA. Enfermagem e aleitamento materno: combinando práticas seculares. Rev Esc Enf USP. 2000; 34: 362-9.

10. Toma TS, Rea, MF. Benefícios da amamentação para a saúde da mulher e da criança: um ensaio sobre as evidências. Cad Saúde Pública. 2008; 24(Supl 2): 235-46.

11. Hanson LA, Telemo E. Immunobiology and epidemiology of breastfeeding in relation to prevention of infections from a global perspective. In: Ogra PL, Mestecky J, Lamm ME, Strober W, Bienenstock J, McGhee J. Mucosal Immunology. San Diego: Academic Press, 1999. p. 1501-10.

12. Betrán AP, Onís M, Lauer JA, Villar J. Ecological study of effect of breast feeding on infant mortality in Latin America. BMJ. 2001; 323: 1-5.

13. Venâncio SI. Dificuldades para o estabelecimento da amamentação: o papel das práticas assistenciais das maternidades. J Pediatr (Rio J). 2003; 79: 1-2.

14. UNICEF. Oficina de Uruguay, RUANDI, Ministerio de Salud Pública. Programa Nacional de Salud de la Niñez. Encuesta de lactancia, estado nutricional y alimentación complementaria en niños menores de 24 meses atentidos por servicios público y mutuales de Montevideo e interior del país / María Isabel Bove, Florencia Cerutti. Montevideo; 2007.

15. Brasil. Ministério da Saúde. Município que promove a amamentação promove a saúde.
Prêmio Bibi Vogel. Pacto nacional pela redução da mortalidade materna e neonatal. Brasília; 2005.

16. Vieira GO, Silva LR, Vieira TO, Almeida JAG, Cabral VA. Hábitos alimentares de crianças menores de um ano amamentadas e não amamentadas. J Pediatr (Rio J). 2004; 80: 411-6.

17. Brasil. Ministério da Saúde, Organização Pan-Americana de Saúde. Dez passos para uma alimentação saudável. Guia alimentar para crianças menores de dois anos. Brasília; 2002a.

18. Devincenzi UM, Mattar MJG, Cintra EM. Nutrição no primeiro ano de vida. In: Silva SMCS, Mura JD’AP. Tratado de alimentação, nutrição e dietoterapia. São Paulo: Roca, 2007. p. 319-45.

19. Saliba NA, Zina LG, Moimaz SAS, Saliba O. Frequência e variáveis associadas ao aleitamento materno em crianças com até 12 meses de idade no município de Araçatuba, São Paulo, Brazil. Rev Bras Saúde Matern Infant. 2008; 8: 481-90.

20. Hanson LA. Breastfeeding provides passive and likely long-lasting active immunity. Ann Allergy Asthma Immunol. 1998; 81: 523-37.

21. Teruya K, Coutinho SB. Sobrevivência infantil e aleitamento materno. In: Rego JD. Aleitamento materno. São Paulo: Atheneu, 2001. p. 5-20.

22. Edmond KM, Zandoh C, Quigley MA, Amenga-Etego S, Owusu-Agyei S, Kirkwood BR. Delayed breastfeeding initiation increases risk of neonatal mortality. Pediatrics. 2006; 117: 380-6.

23. Carbonare SB, Carneiro-Sampaio MMS. Composição do Leite Humano - Aspectos Imunológicos. In: Rego, JD. Aleitamento Materno. São Paulo: Atheneu, 2001. p. 83-97.

24. Carneiro-Sampaio MMS, Silva MLM, Carbonare SB, Palmeira P, Delneri MT, Honório AC, Trabulsi LR. Breast-feeding protection against enteropathogenic 
Escherichia coli. Rev Microbiol. 1996; 27: 120-5.

25. Costa COM, Queiroz SS, Nóbrega FJ, Vitolo MR, Sole D. Total proteins, albumin, globulin, immunoglobulins (A, $\mathrm{M}, \mathrm{G}$ ) and C3 complement fraction in the colostrum of adolescent nursing mothers of preterm infants. In: Nóbrega FJ. Human milk composition. São Paulo: Revinter, 1996. p. 83-98.

26. Lönnerdal B. Regulation of mineral and trace elements in human milk: exogenous and endogenous factors. Nutr Rev. 2000; 58: 223-9.

27. Brasil. Ministério da Saúde. Secretaria de Políticas de Saúde. Área de Saúde da Criança. Atenção humanizada ao recémnascido de baixo-peso: método mãecanguru: manual do curso. Brasília; 2002b.

28. Vinagre RD, Diniz EMA. O leite humano e sua importância na nutrição do recémnascido prematuro. São Paulo: Atheneu, 2001. p. 142.

29. Feferbaum R, Quintal VS. Nutrição enteral do recém-nascido pré-termo. Pediatr Modern. 2000; 36: 133-40.

30. Fernandes RM, Carbonare SB, CarneiroSampaio MM, Trabulsi LR. Inhibition of enteroaggregative Escherichia coli adhesion to Hep-2 cells by secretory immunoglobulin A from human colostrum. Pediatr Infect Dis J. 2001; 20: 672-8.

31. Novak FR, Almeida JAG, Vieira GO, Borba LM. Colostro humano: fontes naturais de probióticos? J Pediatr (Rio J). 2001; 77: 265-71.

32. Jackson KM, Nazar AM. Breastfeeding, the immune response, and long-term health. J Am Osteopath Assoc. 2006; 106: 203-7.
33. Brown KH, Black RE, Romaña GL, Kanashiro HC. Infant-feeding practices and their relationship with diarrheal and other diseases in Huascar (Lima), Peru. Pediatrics. 1989; 83: 31-40.

34. Rego JD. Amamentando um prematuro. In: Rego JD. Aleitamento materno: um guia para pais e familiares. São Paulo: Atheneu, 2002. p. 179-86.

35. Bernt KM, Walker WA. Human milk as a carrier of biochemical messages. Acta Paediatr. 1999; 88 (suppl 430): 27-41.

36. Newburg DS, Ruiz-Palacios GM, Morrow AL. Human milk glycans protect infants against enteric pathogens. Annu Rev Nutr. 2005; 25: 37-58.

37. Penders J, Thijs C, Vink C, Stelma FF, Snijders B, Kummeling I, et al. Factors influencing the composition of the intestinal microbiota in early infancy. Pediatrics. 2006; 118: 511-21.

38. Vitolo MR. Aspecto nutricional do leite humano. In: Anais do VII Encontro Paulista de Aleitamento Materno. São Paulo; 1997. p. 33.

39. Goldman AS, Ogra PL. Anti-infectious and infectious agents in human milk. In: Ogra PL, Mestecky J, Lamm ME, Strober W, Bienenstock J, McGhee J. Mucosal Immunology. San Diego: Academic Press, 1999. p. 1511-21.

40. Nóbrega, FJ. A importância nutricional do leite materno. In: Rego JD. Aleitamento Materno. Rio de Janeiro: Atheneu, 2001. p. 59-82.

41. Gouvêa LC. Aleitamento materno. In: Lopez FA, Brasil ALD. Nutrição e Dietética em Clínica Pediátrica. São Paulo: Atheneu, 2003. p.17-36.

42. Xanthou M. Immune protection of human milk. Biol Neonate. 1998; 74: 121-33.

43. Honório-França AC, Carvalho MPSM, Isaac L, Trabulsi LR, Carneiro-Sampaio MMS. Colostral mononuclear phagocytes 
are able to kill enteropathogenic Escherichia coli opsonized with colostral IgA. Scand J Immunol. 1997; 46: 59-66.

44. Russel MW, Kilian M, Lamm ME. Biological actives of IgA. In: Ogra PL, Mestecky J, Lamm ME, Strober W, Bienenstock J, McGhee J. Mucosal Immunology. San Diego: Academic Press, 1999. p.225-40.

45. Carbonare SB, Silva MLM, Palmeira P, Carneiro-Sampaio MMS. Human colostrum IgA antibodies reacting to Enteropathogenic Escherichia Coli (EPEC) antigens and their persistence in the faeces of a breast-fed infant. J Diarrhoeal Dis Res. 1997; 15: 53-8.

46. Carvalho CF, Silva MGF. Avaliação do desmame precoce e suas implicações infecciosas nas crianças atendidas no ambulatório de um hospital terciário. Arq Ciênc Saúde. 2005; 12: 129-32.

47. Broor S, Pandey RM, Ghosh M, Maitreyi RS, Lodha R, Singhal T, Kabra KS. Risk factors for severe acute lower respiratory tract infection in under-five children. Indian Pediatr. 2001; 38: 1361-9.

48. Oddy WH, Sly PD, Klerk NH, Landau LI, Kendall GE, Holt PG, Stanley FJ. Breast feeding and respiratory morbidity in infancy: a birth cohort study. Arch Dis Child. 2003; 88: 224-8.

49. Kerner JA Jr. Use of infant formulas in preventing or postponing atopic manifestations. J Pediatr Gastroenterol Nutr. 1997; 24: 442-6.

50. Wold AE, Adlerberth I. Does breastfeeding affect the infant's immune responsiveness? Acta Paediatr. 1998; 87: 19-22.

51. Carvalho Júnior, FF. Apresentação clínica da alergia ao leite de vaca com sintomatologia respiratória. J Pneumol. 2000; 27: 17-24.

52. August A, Mueller C, Weaver V, Polanco TA, Walsh ER, Cantorna MT. Nutrients, nuclear receptors, inflammation, immunity lipids, PPAR, and allergic asthma. J Nutr. 2006; 136: 695-9.

53. Kalliomäki M, Ouwehand A, Arvilommi $\mathrm{H}$, Kero P, Isolauri E. Transforming growth factor-beta in breast milk: a potential regulator of atopic disease at an early age. J Allergy Clin Immunol. 1999; 104: 12517.

54. Carbajal CC. Estado de salud en los niños lactados por más de 4 meses. Rev Cubana Pedriatr. 2000; 72: 275-80.

55. Savilahti E, Siltanen M, Kajosaari M, Vaarala O, Saarinen KM. IgA antibodies, TGF-beta1 and -beta2, and soluble CD14 in the colostrum and development of atopy by age 4. Pediatr Res. 2005; 58: 1300-5.

56. Osterlund P, Smedberg T, Hakulinen A, Heikkilä H, Järvinen KM. Eosinophil cationic protein in human milk is associated with development of cow's milk allergy and atopic eczema in breast-fed infants. Pediatr Res. 2004; 55: 296-301.

57. Pabst HF, Spady DW, Pilarski LM, Carson MM, Beeler JA, Krezolek MP. Differential modulation of the immune response by breast- or formula-feeding of infants. Acta Paediatr. 1997; 86: 1291-7.

58. Hawkes JS, Neumann MA, Gibson RA. The effect of breast feeding on lymphocyte subpopulations in healthy term infants at 6 months of age. Pediatr Res. 1999; 45: 648-51.

59. Busse WW, Lemanske RF Jr. Asthma. N Engl J Med. 2001; 344: 350-62.

60. Hasselbalch H, Engelmann MD, Ersboll AK, Jeppesen DL, Fleischer-Michaelsen K. Breast-feeding influences thymic size in late infancy. Eur J Pediatr. 1999; 158: 964-7.

Recebido em 14 de março de 2009 Modificado em 26 de novembro de 2009 Aceito em 14 de janeiro de 2010 